\title{
Effect of Medicago sativa Mhb1gene expression on defense response of Arabidopsis thaliana plants
}

\author{
Anna Maassen and Jacek Hennig ${ }^{\bowtie}$ \\ Institute of Biochemistry and Biophysics, Polish Academy of Sciences, Warszawa, Poland
}

\begin{abstract}
Besides the previously described nitric oxide-detoxification activity we identified new features of class-1 nonsymbiotic hemoglobin from Medicago sativa (Mhb1). Under in vitro conditions, using peroxidase in-gel activity assay, the Mhb1 protein was shown to possess also peroxidase-like activity. Due to this activity, in the presence of nitrite and hydrogen peroxide, the protein can mediate autonitration and nitration of other proteins at tyrosine residues, as revealed by tandem mass spectrometry and immune assay approaches. Mhb1 through its multifunctional activities can affect different components of signal transduction cascades operating during plant response to infections. This influence is manifested by Mhb1-mediated selective up-regulation of expression of certain pathogen inducible genes in Pseudomonas syringae infected Arabidopsis thaliana plants which overproduce Mhb1, as revealed by reverse transcription-quantitative real-time PCR analysis. Changes in expression level of these genes can influence such processes as synthesis of secondary metabolites, protein degradation and biosynthesis of ethylene. They can also result in alteration of pathogen-induced defense response of Mhb1 transgenic plants.
\end{abstract}

Keywords: nitric oxide, nitrotyrosine, non-symbiotic hemoglobin, pathogen infection, peroxidase activity, Arabidopsis thaliana

Received: 28 March, 2011; revised: 10 May, 2011; accepted: 17 June, 2011; available on-line: 4 July, 2011

\section{INTRODUCTION}

Non-symbiotic hemoglobins (nsHbs) are widely distributed in higher plants. They are organized in two classes differing in affinity for $\mathrm{O}_{2}$. The nsHbs are involved in nitric oxide ( $\mathrm{NO}$ ) detoxification in plants. Several nsHbs, mainly from class-1, have been shown to possess -NO detoxifying activity similar to that of mammalian hemoglobins (Hbs) (reviewed in Perazzolli et al., 2006; Garrocho-Villegas et al., 2007; Hoy \& Hargrove, 2008). As in, mammals $\mathrm{NO}$ is a signaling molecule which plays a pivotal role in plant responses to biotic and abiotic stresses and also during developmental processes (reviewed in Hong et al., 2008; Neill et al., 2008; Wilson et al., 2008). Expression of genes coding for class-1 nsHbs is induced in plants under hypoxia. It is proposed that the main function of this group of $\mathrm{Hbs}$ is protection against nitrosative stress associated with hypoxia. Overexpression of class- 1 nsHbs decreases the level of $\mathrm{NO}$ accumulated under hypoxia and increases plant tolerance to this stress (reviewed in Perazzolli et al., 2006). Some nsHbs have also been shown to possess peroxidase-like activity similar to that of mammalian Hbs (Sakamoto et al., 2004; Violante-Mota et al., 2010).

Recent studies showed that nsHbs of class-1 can also be involved in plant response to pathogen infection. However, various nsHbs, despite belonging to the same class, act differently in this process (Perazzolli et al., 2004; Qu et al., 2005; 2006; Nagata et al., 2008). Expression of cotton nsHb GhHb1 was shown to be significantly induced by infection with the fungal pathogen Verticillium dabliae (Qu et al., 2005). Overexpression of alfalfa $M b b 1$ and $G b H b 1$ respectively, in transgenic tobacco and Arabidopsis plants, increased their pathogen resistance and caused up-regulation of certain defense genes (Seregélyes et al., 2003; 2004; Qu et al., 2006). In particular, Mbb1-transgenic tobacco displayed reduced necrosis formation in response to tobacco necrosis virus (TNV) and Pseudomonas syringae pv. phaseolicola (Seregélyes et al., 2003). In these plants significant up-regulation of a pathogen-inducible pathogenesis related PR1a gene was observed after infection with $P$. syringae $\mathrm{pv}$. maculicola (Seregélyes et al., 2004). Infected Mbb1-transgenic tobacco also displayed a higher level of salicylic acid and superoxide anion $\left(\mathrm{O}_{2}^{--}\right)$, molecules involved in plant response to pathogen infection (Seregélyes et al., 2003).

In this report we show that $M b b 1$-transgenic $A$. thaliana plants infected with an avirulent strain of $P$. syringae pv. tomato display up-regulation of several pathogeninducible genes. Such impact of Mhb1 on pathogen-inducible gene expression can be connected with various pseudo-enzymatic activities of the Mhb1 protein. Recombinant Mhb1 (rMhb1), besides the previously shown 'NO detoxification activity, also displays a peroxidaselike activity. This activity enables rMhb1 in the presence of hydrogen peroxide $\left(\mathrm{H}_{2} \mathrm{O}_{2}\right)$ to oxidize nitrite $\left(\mathrm{NO}_{2}^{-}\right)$to nitrogen dioxide $\left(\mathrm{NO}_{2}\right)$ which is a nitrating agent of biomolecules. We demonstrated that rMhb1 undergoes autonitration and also can effect nitration of other protein.

\section{MATERIALS AND METHODS}

Purification of recombinant Mhb1. To investigate peroxidase-like activity of Mhb1, amino-terminally His-tagged recombinant Mhb1 protein (rMhb1) was

e-mail: jacekh@ibb.waw.pl

Abbreviations: BSA, bovine serum albumin; CBB, Coomassie brilliant blue; DAB, diaminobenzidine; Hbs, hemoglobins; LC-MS-MS/ MS, liquid chromatography-tandem mass spectrometry; Mhb1, class-1 non-symbiotic hemoglobin from Medicago sativa; nsHbs, non-symbiotic hemoglobins; PR, pathogenesis related proteins; pv., pathovar; ROS, reactive oxygen species; RT-PCR, reverse transcription-PCR; RT-qPCR, reverse transcription-quantitative realtime PCR 
overproduced in Escherichia coli BL21(DE) strain. The p'TrcHis B/Mhb1 plasmid containing full-length Mbb1 cDNA, described previously, was used (Seregélyes et al., 2004). rMhb1 was purified using a three-step purification process including precipitation with ammonium sulphate, Ni-affinity chromatography, and ion-exchange chromatography. The protein was purified to homogeneity as confirmed by LC-MS-MS/MS analysis. For details see Supplementary Methods at www.actabp.pl (A.1). Purified rMhb1 extract was concentrated to 0.5 $\mu \mathrm{g} / \mu \mathrm{l}$ in phosphate-buffered saline ( $\mathrm{pH}$ 7.4) (0.08 M $\mathrm{Na}_{2} \mathrm{HPO}_{4}, 0.02 \mathrm{M} \mathrm{NaH} \mathrm{PO}_{4}, 0.01 \mathrm{M} \mathrm{NaCl}$ ) using an Amicon concentrator (Amicon Ultra-15 centrifugal filter device, Millipore).

Peroxidase activity assay in gel. Three micrograms of rMhb1 was resolved by $5 \%$ native polyacrylamide gel electrophoresis. For detection of peroxidase activity, the gel was immersed for $1 \mathrm{~h}$ in $0.1 \mathrm{M}$ potassium phosphate buffer ( $\mathrm{pH} 7.0$ ) containing $2 \mathrm{mM} \mathrm{H}_{2} \mathrm{O}_{2}$ and $0.1 \%(\mathrm{w} / \mathrm{v})$ diaminobenzidine (DAB). Alternatively, the gel was immersed for $15 \mathrm{~min}$ in $0.1 \mathrm{M}$ potassium phosphate buffer ( $\mathrm{pH} 7.0$ ) containing $2 \mathrm{mM} \mathrm{H} \mathrm{O}_{2}, 0.225 \mathrm{mM}$ p-coumaric acid and $1.25 \mathrm{mM}$ luminol. The chemiluminescence signal derived from peroxidase-catalyzed oxidation of luminol was detected using X-ray films (Foton Xs-1N, FOTON). Optionally, potassium cyanide $(\mathrm{KCN})$ was used as an inhibitor at a final concentration of $5 \mathrm{mM}$. A parallel gel was stained with Coomassie brilliant blue (CBB) for confirmation of the presence of protein.

Peroxidase-mediated nitration of protein tyrosine. rMhb1 $(0.5 \mu \mathrm{g})$ was incubated in phosphate buffered saline with $1 \mathrm{mM} \mathrm{H}_{2} \mathrm{O}_{2}$ and $1 \mathrm{mM} \mathrm{NaNO}_{2}$ in a total volume of $10 \mu \mathrm{l}$ of the reaction mixture at $25^{\circ} \mathrm{C}$ for $1 \mathrm{~h}$. Optionally, $2 \mu \mathrm{g}$ BSA was added. Oxidation of $\mathrm{NO}_{2}{ }^{-}$to $\cdot \mathrm{NO}_{2}$ was manifested by nitrotyrosine formation.

Detection of nitrotyrosine by Western blotting. Nitrotyrosine was detected using primary rabbit polyclonal anti-nitrotyrosine antibody diluted 1:1000 (Upstate Biotechnology) and secondary sheep anti-rabbit antibody conjugated with horseradish peroxidase diluted 1:80000 (Sigma). For details see Supplementary Methods at www. actabp.pl (A.2). For confirmation of protein presence a duplicate gel was stained with CBB.

Detection of nitrotyrosine by liquid chromatography-tandem mass spectrometry (LC-MS-MS/MS). Prior to analysis rMhb1 was subjected to digestion with trypsin, reduction and alkylation. The resulting peptide mixture was analyzed by liquid chromatography coupled to an LTQ FT ICR mass spectrometer (Hybrid-2D-Linear Quadrupole Ion Trap-Fourier Transform Ion Cyclotron Resonance Mass Spectrometer, Thermo Electron Corp., San Jose, CA, USA). The acquired raw data were processed by Mascot Distiller followed by Mascot Search (Matrix Science, London, UK) against NCBI non-redundant database. For details see Supplementary Methods www.actabp.pl (A.3).

Construction of transgenic plants. The previously described $\mathrm{pROK} 2 / \mathrm{Mhb} 1$ construct containing full-length Mbb1 cDNA (Seregélyes et al., 2003) was used for transformation of $A$. thaliana $\mathrm{L}$. ecotype Col-0 plants by the floral dipping method (Clough \& Bent, 1998). The transgenic line obtained by transformation with an empty vector was used as a control. Plants, were grown in growth chambers as was described by Talarczyk et al. (2002).

Plant infection. Four-week-old transgenic $A$. thaliana plants from F3 generation were infected with Pseudomonas syringae pv. tomato DC3000 AvrRPM1 strain at a concentration of $10^{6} \mathrm{cfu} / \mathrm{ml}$ in $10 \mathrm{mM} \mathrm{MgCl}$. The whole area of the leaf was infiltrated with the bacterial suspension by pressing the solution into the leaf at the abaxial side with a needleless $1-\mathrm{ml}$ syringe. Control leaves were mock-inoculated with $10 \mathrm{mM} \mathrm{MgCl}$. Leaves were collected at 0 and $24 \mathrm{~h}$ post infection.

Reverse transcription reaction. Total RNA was isolated using the method of Chomczynski and Sacchi, (1987) with modifications for plant RNA (according to an MRC Company protocol) using RNA extraction reagent: $38 \%(\mathrm{v} / \mathrm{v})$ phenol, $0.8 \mathrm{M}$ guanidine thiocyanate, $0.4 \mathrm{M}$ ammonium thiocyanate, $0.1 \mathrm{M}$ sodium acetate $(\mathrm{pH} 5.0), 5 \%(\mathrm{w} / \mathrm{v})$ glycerol. One microgram of RNA after DNase treatment (Promega) was used for the reverse transcription reaction in $20 \mu \mathrm{l}$ volume with oligo (dT) 18 primer and M-MuLV reverse transcriptase (according to a Fermentas Company protocol) for firststrand cDNA synthesis.

Quantitative real-time PCR (qPCR). Primers from "Primer library for Arabidopsis pathogen inducible genes" (Sigma) were used with „SYBR Green JumpStart Taq ReadyMix for Quantitative PCR" (Sigma). Primers corresponding to the following genes were used (gene name is followed by the corresponding genome locus in brackets): ACS6 (1-aminocyclopropane-1-carboxylate synthase 6 - ACC synthase 6, AT4G11280), ACT2 (actin 2, AT3G18780), CML41 (calmodulin-related protein 41, AT3G50770), MATX (matrixin family protein with peptidase activity, AT1G24140), MO2 (monooxygenase 2, AT4G38540), PAD4 (phytoalexin-deficient 4 protein with triacylglycerol lipase activity, AT3G52430), PR1 (pathogenesis-related protein 1, AT2G14610), PR4 (pathogenesis-related protein 4, AT3G04720), PXMT1 ( $S$-adenosyl-L-methionine-dependent paraxanthine methyltransferase 1, AT1G66700), RHA1A (RING$\mathrm{H} 2$ finger protein with ubiquitin-protein ligase activity, AT4G11370), SDR (short-chain dehydrogenase/ reductase family protein, AT2G47130). Amplification, data acquisition, and data analysis were carried out using GeneAmp 5700 Sequence Detection System (Applied Biosystem). The expression level of the genes, shown in arbitrary units, was estimated by relative quantification process, using ACT2 gene for normalization. For details see Supplementary Methods at www.actabp.pl (A.4).

\section{RESULTS AND DISCUSSION}

\section{Peroxidase-like activity of rMhb1 protein}

Mhb1 exhibits peroxidase-like activity similarly to ani$\mathrm{mal} \mathrm{Hbs}$ and nsHbs from $A$. thaliana and rice (Bao \& Williamson, 1997; Sakamoto et al., 2004; Violante-Mota et al., 2010). Peroxidases catalyze the oxidation of different substrates in the presence of $\mathrm{H}_{2} \mathrm{O}_{2}$. The peroxidase-like activity of rMhb1 was studied by in-gel activity assay in the presence of two substrates, DAB and luminol (Fig. 1). The peroxidase-like activity of rMhb1 was detected in the gel with both substrates and colocalized with the CBB-stained protein. This activity was completely abolished by $\mathrm{KCN}$, an inhibitor of peroxidase. This analysis demonstrated that the rMhb1 protein possesses a peroxidase-like activity.

\section{rMhb1-mediated protein nitration}

Peroxidases can oxidize different substrates including $\mathrm{NO}_{2}^{-}$. In the presence of $\mathrm{H}_{2} \mathrm{O}_{2}$, they oxidize $\mathrm{NO}_{2}{ }^{-}$to $\mathrm{NO}_{2}$ which can react with biomolecules. In the case of proteins, it causes nitration mainly of tyrosine residues 


\section{CBB}

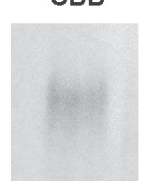

DAB

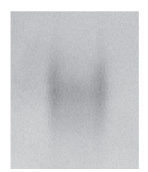

$\mathrm{DAB}+\mathrm{KCN}$ luminol

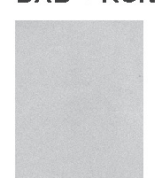

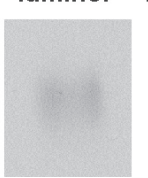

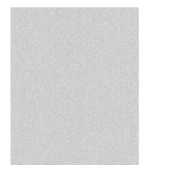

Figure 1. Analysis of peroxidase activity of rMhb1

DAB $0.1 \%$ or $1.25 \mathrm{mM}$ luminol were used as substrates and $5 \mathrm{mM}$ KCN as an inhibitor in in-gel peroxidase assay of purified rMhb1 (3 $\mu \mathrm{g})$ after native polyacrylamide gel (5\%) electrophoresis. For confirmation of protein presence a parallel gel was stained with CBB.

leading to formation of nitrotyrosine (reviewed in Radi, 2004).

Following the observation that rMhb1 exhibits a peroxidase-like activity, its ability to oxidize $\mathrm{NO}_{2}^{-}$and thus to mediate protein nitration was examined. Purified rMhb1 protein was incubated with $\mathrm{NO}_{2}^{-}$and $\mathrm{H}_{2} \mathrm{O}_{2}$ to test its self-nitration ability. Additionally, the reaction was supplemented with a standard nitration target protein, BSA, to test the nitration ability of a coexisting protein. Then, nitration of tyrosine was examined by immunoassay with anti-nitrotyrosine antibodies.

Before evaluation of the results of the nitration test, it should be noted that rMhb1 in the presence of $\mathrm{H}_{2} \mathrm{O}_{2}$ underwent degradation and oligomerisation as revealed by analysis of a CBB-stained duplicate gel (Fig. 2A-I). $\mathrm{NO}_{2}{ }^{-}$partially abolished these $\mathrm{H}_{2} \mathrm{O}_{2}$-dependent rMhb1 rearrangements (Fig. 2A-I, lanes 4 and 5). This suggests that consumption of $\mathrm{H}_{2} \mathrm{O}_{2}$ in the peroxidase-catalyzed nitration competes with $\mathrm{H}_{2} \mathrm{O}_{2}$-dependent degradation.

The observed rMhb1 oligomerisation and degradation could be caused by its oxidative damage, similarly as it was shown the whale myoglobin (Roncone et al., 2005). $\mathrm{H}_{2} \mathrm{O}_{2}$, besides inducing peroxidase-like activity of the myoglobin, was also shown to promote its oxidative damage. The myoglobin could competitively react with the substrate or undergo autodegradation. Myoglobin oligomers were shown to be generated from tyrosyl radicals and heme-protein cross-linked species, both formed by

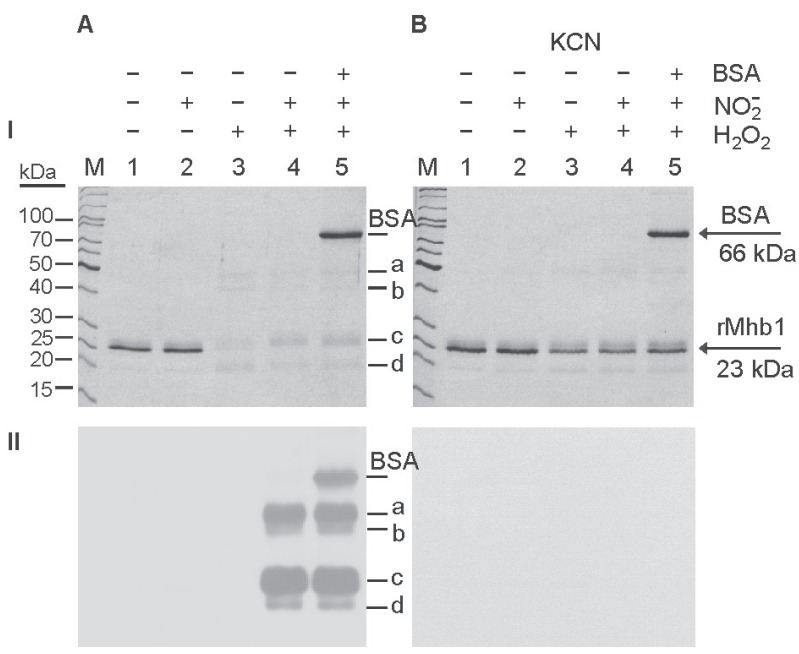

Figure 2. Analysis of nitration of rMhb1 and BSA

rMhb1 $(1 \mu \mathrm{g})$ and/or BSA $(2 \mu \mathrm{g})$ were incubated with $1 \mathrm{mM} \mathrm{NO}_{2}^{-}$ and/or $1 \mathrm{mM} \mathrm{H}_{2} \mathrm{O}_{2}$ at room temperature for $1 \mathrm{~h}$, and then analyzed for protein nitrotyrosine formation by Western blotting (II). I, duplicate SDS/PAGE gel (15\%) stained with CBB; (A) analysis of protein nitration mediated by $\mathrm{rMhb} 1$; (B) corresponding reactions supplemented with $5 \mathrm{mM} \mathrm{KCN}, \mathrm{M}$, molecular mass protein marker; a, rMhb1 dimer; $b$, dimer of degraded rMhb1; c, rMhb1 monomer; $\mathrm{d}$, degraded rMhb1 (around $18 \mathrm{kDa}$ ). peroxidase-catalyzed oxidation. Slight $\mathrm{H}_{2} \mathrm{O}_{2}$-dependent degradation can be also seen in nsHbs from $A$. thaliana tested for their nitrating ability (Sakamoto et al., 2004).

Western blot analysis with anti-nitrotyrosine antibodies revealed that incubation of rMhb1 with $\mathrm{NO}_{2}{ }^{-}$or $\mathrm{H}_{2} \mathrm{O}_{2}$ alone did not cause nitration (Fig. 2A-II; lanes 2 and 3). In contrast, incubation of rMhb1 with both substrates simultaneously resulted in its strong nitration (Fig. 2A-II, lane 4). Additionally, all forms of rMhb1 underwent nitration (Fig. 2A-II; lane 4; bands a-d). Co-incubation of rMhb1 with $\mathrm{BSA}$ in the presence of $\mathrm{NO}_{2}{ }^{-}$and $\mathrm{H}_{2} \mathrm{O}_{2}$ resulted in nitration of both proteins (Fig. 2A-II, lane 5). This study showed that in the presence of $\mathrm{NO}_{2}^{-}$and $\mathrm{H}_{2} \mathrm{O}_{2} \mathrm{rMhb} 1$ can mediate tyrosine nitration of itself and other proteins.

The rMhb1-mediated nitration of BSA was rather less intense than rMhb1 auto-nitration even though BSA was present at a twice higher concentration and possessed 21 tyrosine residues. It is possible that $\mathrm{NO}_{2}$ produced by rMhb1 is first trapped mainly by neighboring tyrosine residues of $\mathrm{rMhb1}$.

The nitration reaction was completely abolished by $\mathrm{KCN}$, demonstrating that nitrotyrosine formation was dependent on the peroxidase-like activity of rMhb1 (Fig. 2B-II; lanes 4 and 5). Although $\mathrm{KCN}$ inhibited protein nitration significantly, it affected $\mathrm{H}_{2} \mathrm{O}_{2}$-dependent degradation and oligomerisation of rMhb1 only partially (Fig. 2B-I, lanes 3, 4 and 5). This suggests that the $\mathrm{H}_{2} \mathrm{O}_{2}$ effect on rMhb1 does not fully depend on the peroxidase-like activity of rMhb1. Increased of KCN concentrations (up to $25 \mathrm{mM}$ ) did not inhibit the effect of $\mathrm{H}_{2} \mathrm{O}_{2}$ either (not shown).

Mhb1 contains two tyrosine residues (Tyr107 and Tyr145). LC-MS-MS/MS analysis of rMhb1 after nitration revealed that both tyrosine $(\mathrm{Y})$ residues underwent nitration. In the nitrated sample two different Y-containing peptides were identified with a mass shift of $45 \mathrm{Da}$ relative to the masses in an untreated sample, which is the expected mass associated with the nitro group attachment (not shown). The nitro group in these peptides was mapped to the tyrosine residue. A comparative analysis of $\mathrm{m} / \mathrm{z}$ (mass to charge ratio) values of daughter ions from corresponding Y-containing peptides in the control and nitrated sample, confirming the occurrence of this modification in rMhb1 subjected to nitration reaction, is presented in Fig. 3. The shift of $m / z 45$ seen in the Y-containing singly charged $(+)$ daughter ions from the nitrated sample versus the control one confirms the nitration of both tyrosine residues. All the modifications of rMhb1, such as nitration or $\mathrm{H}_{2} \mathrm{O}_{2}$-mediated oligomerisation and degradation, could influence its activity and function.

The results clearly demonstrate that, due to its peroxidase-like activity Mhb1, is capable of utilizing $\mathrm{NO}_{2}{ }^{-}$to produce the nitrating agent $\cdot \mathrm{NO}_{2}$ and thus lead to tyrosine nitration similarly as animal Hbs (Grzelak et al., 2001).

\section{Analysis of pathogen inducible genes in Mhb1-transgenic A. thaliana plants}

Possessing NO-detoxification and peroxidase-like activity Mhb1 can interfere both with ' $\mathrm{NO}$ and $\mathrm{H}_{2} \mathrm{O}_{2}$ metabolism. Thus it can contribute to the modulation of plant response to infection, which has been shown to depend on $\mathrm{NO}$ and reactive oxygen species (ROS), including $\mathrm{H}_{2} \mathrm{O}_{2}$ and $\mathrm{O}_{2}^{--}$(reviewed in Hofius et al., 2007; Mur et al., 2008). 'NO and ROS are produced in high amounts during infection and they are key elements of plant resistance response. The balance between $\mathrm{NO}$ and 

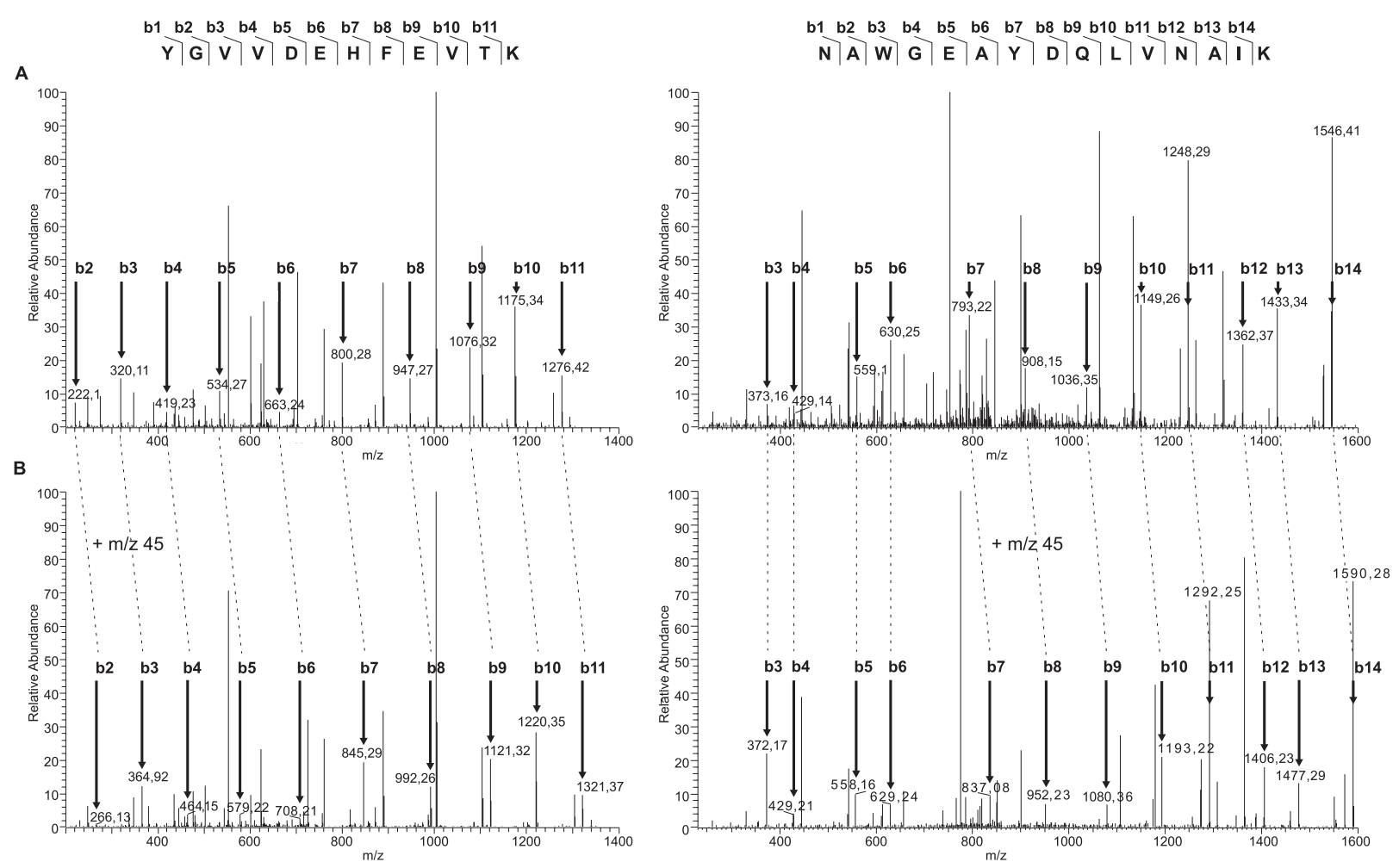

Figure 3. Comparative analysis of LC-MS-MS/MS spectra of Y-containing peptides from control and nitrated sample of rMhb1 protein

rMhb1 $(2 \mu \mathrm{g})$ was incubated with $1 \mathrm{mM} \mathrm{NO}_{2}^{-}$and $1 \mathrm{mM} \mathrm{H}_{2} \mathrm{O}_{2}$ at room temperature for $1 \mathrm{~h}$. Non-treated rMhb1 protein was used as a control. Prior to mass spectrometry (LC-MS-MS/MS) analysis, protein samples were subjected to standard procedures of trypsin digestion, reduction and alkylation. Figure shows a comparison of fragmentation spectra of two different tyrosine (Y)-containing peptides (YGVVDEHFEVT and NAWGEAYDQLVNAIK) from control sample (A) and sample subjected to nitration (B). Peaks in spectra represent daughter ions ( $b$ - and $y$-series ions representing $\mathrm{N}$ - and C-terminal parts of a precursor peptide, respectively) which result from fragmentation of precursor peptide during the MS/MS procedure. For clarity, singly $(+)$ charged $(z=1)$ peptide fragments from $b$-series daughter ions, as the most represented b-ions in the spectra, were considered in the comparative analysis. In the analysis of YGVVDEHFEVT and NAWGEAYDQLVNAIK peptides b2-b11 ions and b3-b14 ions, respectively, were included. By comparing $\mathrm{m} / \mathrm{z}$ values of b-ions from the Y-containing peptides of two analyzed samples a 45 Da shift can be noted in the Y-containing ions corresponding to the precursor peptides from rMhb1 subjected to nitration reaction.

ROS is an important factor for creating efficient defense response (Delledonne et al., 1998; 2001; de Pinto et al., 2002). They participate in activation of signaling pathways involved in expression of defense genes in plants and also exert a cytotoxic effect on the pathogen and/or infected tissue, thus preventing pathogen spread.

While the NO-detoxification activity of plant nsHbs has been shown to lower the $\mathrm{NO}$ level in nsHb-overexpressing plants (reviewed in Perazzolli et al., 2006), the influence of the peroxidase-like activity of nsHbs on the $\mathrm{H}_{2} \mathrm{O}_{2}$ level in planta is still not clear. There are some contradictory results concerning the role of nsHbs as peroxidases in $\mathrm{H}_{2} \mathrm{O}_{2}$ metabolism in plants. It was shown that Arabidopsis plants expressing class-1 nsHb Ahb1 exhibited a decreased cellular level of $\mathrm{H}_{2} \mathrm{O}_{2}$ generated during hypoxia (Yang et al., 2005). The observed increased activity of the antioxidant system involved in scavenging of $\mathrm{H}_{2} \mathrm{O}_{2}$ during hypoxic treatment suggested that this system might be responsible for the low $\mathrm{H}_{2} \mathrm{O}_{2}$ level in those Abb1-transgenic plants. Overexpression of barley nsHbs in alfalfa plants did not significantly change the level of $\mathrm{H}_{2} \mathrm{O}_{2}$ a produced under hypoxia stress although an increased activity of the antioxidant system was observed (Igamberdiev et al., 2006).

Violante-Mota et al. (2010) suggest that peroxidase-like activity of $\mathrm{nsHbs}$ is not of physiological significance in planta. Those authors state that it is unlikely that the rice class- $1 \mathrm{nsHb}$ they studied, and probably other similar plant nsHbs, function in vivo as peroxidases and influence the plant physiology by modulating levels of $\mathrm{H}_{2} \mathrm{O}_{2}$. They showed that the rice nsHb had a weak peroxidase activity compared with the horseradish peroxidase. However, it partially protected E. coli cells expressing recombinant rice $\mathrm{nsHb}$ from stress caused by $\mathrm{H}_{2} \mathrm{O}_{2}$ treatment. Those results do not exclude an influence of nsHbs on $\mathrm{H}_{2} \mathrm{O}_{2}$ metabolism in plants. The nsHbs can still play a modulating role in this process.

Nevertheless, we showed that overexpression of Mhb1 can disturb the $\mathrm{H}_{2} \mathrm{O}_{2}$ metabolism in planta. Moreover, Mhb1 can thus contribute together with other processes to the synthesis of $\mathrm{NO}_{2}$; the latter, as a nitrating agent, can influence the activity and stability of biomolecules both in the infected host and the invading pathogen. Protein nitration can constitute a novel level of regulation in signaling cascades operating during plant response to infection. Tyrosine nitration has been shown to increase during defense responses in plants (Saito et al., 2006; Romero-Puertas et al., 2007; Chaki et al., 2009). In mammalian tissues nitration of proteins increases in various pathologies. Nitrotyrosine is commonly detected in infectious and inflammatory diseases (Haddad et al., 1994; Keita et al., 2000; Hickman-Davis et al., 2001; Sittipunt et 
al., 2001). Protein nitration has been shown in mammalian cells to contribute to cellular signaling in many different processes, including disease development, since it can influence the activity and function of proteins thus modified (reviewed in Monteiro et al., 2008; Ischiropoulos, 2009).

Mhb1, by possessing the nitration ability, could participate in protein nitration in plant cells during infection and thus influence the cellular signaling associated with plant defense response.

Mhb1, with its moderate peroxidase-like activity, seems not to be a major player in the metabolism of $\mathrm{H}_{2} \mathrm{O}_{2}$ or in protein nitration in planta. Nevertheless, it can be crucial for these processes due to the interaction of substrates and Mhb1 protein. The peroxidase-like activity of Mhb1 manifests in its autonitration and nitration of selected proteins in vitro (recombinant potato 1,3- $\beta$-glucanase rGluB20-2, unpublished results), which can modulate their activity. Additionally, the nuclear and cytosolic localization of Mhb1 in plant cells (Seregélyes et al., 2000) can contribute to the processes of nitration and metabolism of $\mathrm{H}_{2} \mathrm{O}_{2}$ or ' $\mathrm{NO}$ with different kinetics in these two compartments. The nuclear localization of Mhb1 looks especially interesting because its concentration in nucleus is much higher than in the cytosol or appoplast (Seregélyes et al., 2000). Thus, the through its multiple activities and dual localization Mhb1 can affect different components of signal transduction cascades operating during plant response to infection.

We asked the question of how increasing these activities in planta by Mhb1 overexpression can influence the signaling network of plant defense response manifested by expression of defense genes. We expect that Mhb1 overexpression can influence the processes dependent on molecules which Mhb1 reacts with. The NO-detoxification and peroxidase-like activity of Mhb1 can change the NO/ROS ratio in transgenic plants. Perturbations in the level of these molecules can change the plant response to infection which is dependent on them. Through its nitration activity Mhb1 can also additionally influence the signaling cascades associated with this process by modification of engaged proteins.

We considered one of the elements of the plant immune response - expression of genes associated with the process of plant defense response to infection, in Mbb1transgenic plants. To study the influence of Mhb1 on plant response to pathogen infection, with special emphasis on pathogen-induced gene expression, two independent transgenic $A$. thaliana lines overproducing Mhb1 versus a control line were analyzed. Plants were infected with an avirulent strain of $P$. syringae pv. tomato DC3000 AvrRPM1. A set of 97 pathogen-inducible genes was analyzed using reverse transcription-PCR (RT-PCR). On the basis of results of this analysis (not shown), ten genes (ACS6, CML41, MATX, MO2, PAD4, PR1, PR4, PXMT1, $\mathrm{RHA1} A, S D R)$, belonging to different functional groups, with the most evident infection-dependent induction, were chosen. As a reference gene, the ACT2 housekeeping gene was used. RT-PCR analysis of the expression profiles of the studied genes revealed induction of their expression due to pathogen infection (see Supplementary Data at www.actabp.pl, Fig. B.1). Differences were observed in the expression levels of the studied genes between the Mbb1-transgenic and control lines before and after challenge with the pathogen.

To study quantitatively the Mhb1 impact on the expression of the analyzed genes during infection, RTqPCR analysis was performed. This analysis showed that the expression level of the ACS6, MO2, PXMT1 and
RHA1A gene was higher by, respectively, 60, 35, 70 and $40 \%$ (Fig. 4A, B, C, D) in the Mbb1-transgenic lines than in the control line.

The higher expression of ACS6, MO2, PXMT1 and $\mathrm{RHA1} A$ genes in the transgenic Mhb1 lines suggests a marked impact of Mhb1 on the transcriptional regulation of these genes. In the case of MO2 and PXMT1 include synthesis of secondary metabolites with anti-microbial activity (Aubourg et al., 1999; Naoumkina et al.,

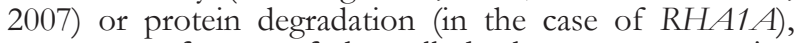
a common feature of the cell death process occurring during defense response to infection (reviewed in Hofius et al., 2007). Particularly interesting was the elevation of expression of the ACS 6 gene encoding a key enzyme in the biosynthesis of ethylene, a plant hormone which participates in plant defense response to infection (reviewed in Hofius et al., 2007). Enhancement of the ACS6 gene expression in the $M b b 1$-transgenic plants can have important implications for the role of this hormone during resistance response.

The expression levels of six other genes, PR4, CML41, SDR, PR1, MATX and PAD4, was similar in both control and Mbb1-transgenic lines ( $P>0.05$; not shown), which suggests that Mhb1 did not interfere with signaling pathways involved in their transcriptional activation. The unchanged expression of the PR1 gene in transgenic Arabidopsis is in contrast with the up-regulation of the PR1a gene in Mbb1-transgenic tobacco (Seregélyes et al., 2004). It is still possible that Mhb1 can affect their expression differently depending on the pathogen and the host plant species.

The selective Mhb1 impact on the expression of the analyzed genes in transgenic $A$. thaliana plants reflects the fact that the genes may be induced by different cascades. The expression of each of these genes can exhibit different sensitivity to the level of molecules influenced by Mhb1. Mhb1, through its multifunctional pseudo-enzymatic activities and dual localization, can influence dif-
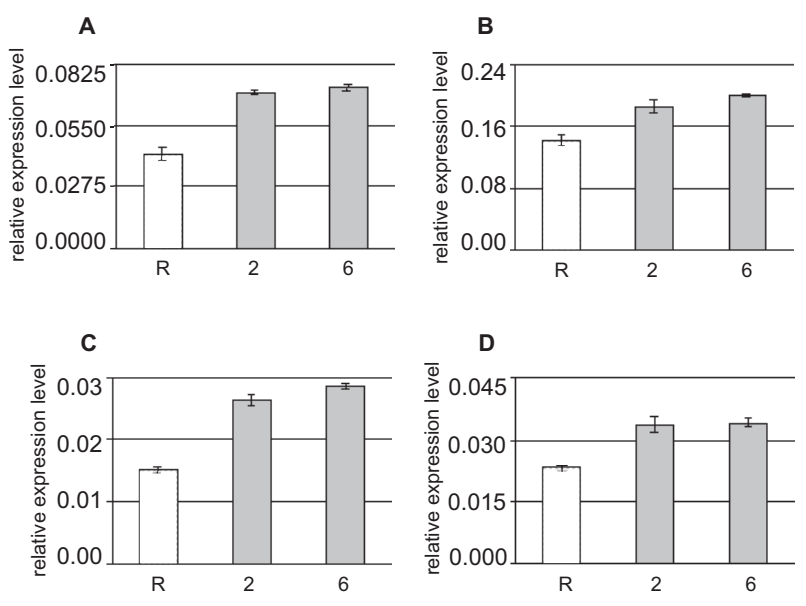

Figure 4. RT-qPCR analysis of expression of pathogen-inducible genes ACS6, MO2, PXMT1, RHA1A in A. thaliana Mhb1-transgenic lines

RT-qPCR analysis was done for samples collected $24 \mathrm{~h}$ post infection with P. syringae pv. tomato DC3000 AvrRPM1. Normalization of expression level of selected genes was performed against the ACT2 gene. Expression values of ACT2 were similar in all lines in Student's test, with $P$-value of $P>0.05$ (not shown). Differences in the expression level of the analyzed genes between control (R) and Mhb1 $(2,6)$ lines were statistically significant $(P<0.05)$. The differences between two Mhb1-transgenic lines were statistically non-significant $(P>0.05)$. (A) ACS6; (B) MO2; (C) PXMT1; (D) RHA1A. 
ferent mechanisms involved in the induction of defense genes and affect them to different extents.

The obtained results support the hypothesis that Mhb1 and other nsHbs can play a role in activation of defense gene expression during infection (Seregélyes et al., 2003; 2004; Qu et al., 2005; 2006). Different pseudoenzymatic activities of nsHbs can have multiple effects on the plant response to infection.

\section{Appendices}

Supplementary Methods (Appendix A), Supplementary Data (Appendix B) at www.actabp.pl.

\section{Acknowledgements}

Special thanks to: Dr. C. Seregélyes for providing us the expression vector containing $M b b 1 \mathrm{cDNA}$ for expression of rMhb1 and its subsequent purification, to Prof. D. Dudits for a stimulating discussion, to Dr. K. Witek for help in protein purification, Dr. J. Debski and Dr. J. Sikora for help and technical assistance in the MS/MS data analysis.

\section{REFERENCES}

Aubourg S, Picaud A, Kreis M, Lecharny A (1999) Structure and expression of three $s r c 2$ homologues and a novel subfamily of flavoprotein monooxygenase genes revealed by the analysis of a 25 $\mathrm{kb}$ fragment from Arabidopsis thaliana chromosome IV. Gene 230: 197-205.

Bao Y, Williamson G (1997) Alpha-Tocopherol enhances the peroxidase activity of hemoglobin on phospholipid hydroperoxide. Redox Rep 3: 325-330.

Chaki M, Fernández-Ocaña AM, Valderrama R, Carreras A, Esteban FJ, Luque F, Gómez-Rodríguez MV, Begara-Morales JC, Corpas FJ, Barroso JB (2009) Involvement of reactive nitrogen and oxygen species (RNS and ROS) in sunflower-mildew interaction. Plant Cell Physiol 50: 265-279.

Chomczynski P, Sacchi N (1987) Single-step method of RNA isolation by acid guanidinium thiocyanate-phenol-chloroform extraction. Anal Biochem 162: 156-159.

Clough SJ, Bent AF (1998) Floral dip: a simplified method for Agrobacterium-mediated transformation of Arabidopsis thaliana. Plant J 16: 735-743.

Delledonne M, Xia Y, Dixon RA, Lamb C (1998) Nitric oxide functions as a signal in plant disease resistance. Nature 394: 585-588.

Delledonne M, Zeier J, Marocco A, Lamb C (2001) Signal interactions between nitric oxide and reactive oxygen intermediates in the plant hypersensitive disease resistance response. Proc Natl Acad Sci USA 98: 13454-13459.

de Pinto MC, Tommasi F, De Gara L (2002) Changes in the antioxidant systems as part of the signaling pathway responsible for the programmed cell death activated by nitric oxide and reactive oxygen species in tobacco Bright-Yellow 2 cells. Plant Physiol 130: 698-708.

Garrocho-Villegas V, Gopalasubramaniam SK, Arredondo-Peter R (2007) Plant hemoglobins: what we know six decades after their discovery. Gene 398: 78-85.

Grzelak A, Balcerczyk A, Mateja A, Bartosz G (2001) Hemoglobin can nitrate itself and other proteins. Biochim Biophys Acta 1528: 97-100.

Haddad IY, Pataki G, Hu P, Galliani C, Beckman JS, Matalon S (1994) Quantitation of nitrotyrosine levels in lung sections of patients and animals with acute lung injury. J Clin Investig 94: 2407-2413.

Hickman-Davis JM, Lindsey JR, Matalon S (2001) Cyclophosphamide decreases nitrotyrosine formation and inhibits nitric oxide production by alveolar macrophages in mycoplasmosis. Infection Immunity 69: 6401-6410.

Hofius D, Tsitsigiannis DI, Jonathan DG, Jones JDG, Mundy J (2007) Inducible cell death in plant immunity. Semin Cancer Biol 17: 166187.

Hoy JA, Hargrove MS (2008) The structure and function of plant hemoglobins. Plant Physiol Biochem 46: 371-379.

Hong JK, Yun BW, Kang JG, Raja MU, Kwon E, Sorhagen K, Chu C, Wang Y, Loake GJ (2008) Nitric oxide function and signalling in plant disease resistance. I Exp Bot 59: 147-154.

Igamberdiev AU, Stoimenova M, Seregélyes C, Hill RD (2006) Class-1 hemoglobin and antioxidant metabolism in alfalfa roots. Planta 223: 1041-1046.
Ischiropoulos H (2009) Protein tyrosine nitration - an update. Arch Biochem Biophys 484: 117-121.

Keita M, Vincendeau P, Buguet A, Cespuglio R, Vallat JM, Dumas M, Bouteille B (2000) Inducible nitric oxide synthase and nitrotyrosine in the central nervous system of mice chronically infected with Trypanosoma brucei brucei. Exp Parasitol 95: 19-27.

Monteiro HP, Arai RJ, Travassos LR (2008) Protein tyrosine phosphorylation and protein tyrosine nitration in redox signaling. Antioxid Redox Signal 10: 843-889.

Mur LA, Kenton P, Lloyd AJ, Ougham H, Prats E (2008) The hypersensitive response; the centenary is upon us but how much do we know? J Exp Bot 59: 501-520.

Nagata M, Murakami E, Shimoda Y, Shimoda-Sasakura F, Kucho K, Suzuki A, Abe M, Higashi S, Uchiumi T (2008) Expression of a class 1 hemoglobin gene and production of nitric oxide in response to symbiotic and pathogenic bacteria in Lotus japonicus. Mol Plant Microbe Interact 21: 1175-1183.

Naoumkina M, Farag MA, Sumner LW, Tang Y, Liu CJ, Dixon RA (2007) Different mechanisms for phytoalexin induction by pathogen and wound signals in Medicago truncatula. Proc Natl Acad Sci USA 104: 17909-17915.

Neill S, Barros R, Bright J, Desikan R, Hancock J, Harrison J, Morris P, Ribeiro D, Wilson I (2008) Nitric oxide, stomatal closure, and abiotic stress. J Exp Bot 59: 165-176.

Perazzolli M, Dominici P, Romero-Puertas MC, Zago E, Zeier J, Sonoda M, Lamb C, Delledonne M (2004) Arabidopsis nonsymbiotic hemoglobin AHb1 modulates nitric oxide bioactivity. Plant Cell 16: 2785-2794.

Perazzolli M, Romero-Puertas MC, Delledonne M (2006) Modulation of nitric oxide bioactivity by plant haemoglobins. $J$ Exp Bot 57: 479-488.

Radi R (2004) Nitric oxide, oxidants, and protein tyrosine nitration. Proc Natl Acad Sci USA 101: 4003-4008.

Romero-Puertas MC, Laxa M, Mattè A, Zaninotto F, Finkemeier I, Jones AME, Perazzolli M, Vandelle E, Dietz K-J, Delledonne M (2007) S-nitrosylation of peroxiredoxin II E promotes peroxynitritemediated tyrosine nitration. Plant Cell 19: 4120-4130.

Roncone R, Monzani E, Labo S, Sanangelantoni AM, Casella L (2005) Catalytic activity, stability, unfolding, and degradation pathways of engineered and reconstituted myoglobins. J Biol Inorg Chem 10: 1124.

Saito S, Yamamoto-Katou A, Yoshioka H, Doke N, Kawakita K (2006) Peroxynitrite generation and tyrosine nitration in defense responses in tobacco BY-2 cells. Plant Cell Physiol 47: 689-697.

Sakamoto A, Sakurao SH, Fukunaga K, Matsubara T, Ueda-Hashimoto M, Tsukamoto S, Takahashi M, Morikawa H (2004) Three distinct Arabidopsis hemoglobins exhibit peroxidase-like activity and differentially mediate nitrite-dependent protein nitration. FEBS Lett 572: 27-32.

Seregélyes C, Mustárdy L, Ayaydin F, Sass L, Kovács L, Endre G, Lukács N, Kovács I, Vass I, Kiss GB, Horváth GV, Dudits D (2000) Nuclear localization of a hypoxia-inducible novel non-symbiotic hemoglobin in cultured alfalfa cells. FEBS Lett 482: 125-130.

Seregélyes C, Barna B, Hennig J, Konopka D, Pasternack TP, Lukàcs N, Fehér A, Horvàth GV, Dudits D (2003) Phytoglobin can interfere with nitric oxide functions during plant growth and pathogenic responses: a transgenic approach. Plant Sci 165: 541-550.

Seregélyes C, Igamberdiev AU, Maassen A, Hennig J, Dudits D, Hill RD (2004) NO-degradation by alfalfa class-1 haemoglobin (Mhb1): a possible link to PR-1a gene expression in Mhb1-overproducing tobacco plants. FEBS Lett 571: 61-66.

Sittipunt C, Steinberg KP, Ruzinski JT, Myles C, Zhu S, Goodman RB, Hudson LD, Matalon S, Martin TR (2001) Nitric oxide and nitrotyrosine in the lungs of patients with acute respiratory distress syndrome. Am J Respir Crit Care Med 163: 503-510.

Talarczyk A, Krzymowska M, Borucki W, Hennig J (2002) Effect of Saccharomyces cerevisiae CTA1 gene expression on response of tobacco plants to tobacco mosaic virus infection. Plant Physiol. 129: 10321044.

Qu ZL, Wang HY, Xia GX (2005) GhHb1: A nonsymbiotic hemoglobin gene of cotton responsive to infection by Verticillium dabliae. Biochim Biophys Acta 1730: 103-113.

Qu ZL, Zhong NQ, Wang HY, Chen AP, Jian GL, Xia GX (2006) Ectopic expression of the cotton non-symbiotic hemoglobin gene GbHb1 triggers defense responses and increases disease tolerance in Arabidopsis. Plant Cell Physiol 47: 1058-1068.

Violante-Mota F, Tellechea E, Moran JF, Sarath G, Arredondo-Peter R (2010) Analysis of peroxidase activity of rice (Oryza sativa) recombinant hemoglobin 1: implications for in vivo function of hexacoordinate non-symbiotic hemoglobins in plants. Phytochemistry 71: 21-26.

Wilson ID, Neill SJ, Hancock JT (2008) Nitric oxide synthesis and signalling in plants. Plant Cell Environ 31: 622-631.

Yang LX, Wang RY, Ren F, Liu J, Cheng J, Lu YT (2005) AtGLB1 enhances the tolerance of Arabidopsis to hydrogen peroxide stress. Plant Cell Physiol 46: 1309-1316. 